\title{
EVALUATION OF THE SEISMIC TOMOGRAPHY TOOL FMTOMO FOR HIGH PERFORMANCE COMPUTING APPLICATIONS
}

\author{
EVALUACIÓN DE LA HERRAMIENTA FMTOMO DE TOMOGRAFÍA SÍSMICA \\ PARA APLICACIONES COMPUTACIONALES DE ALTO RENDIMIENTO
}

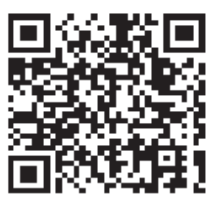

Juan S. López G. ${ }^{1}$, Sergio A. Abreo C. ${ }^{1}$, Oscar M. Reyes T. ${ }^{1}$

1. Escuela de Ingenierías Eléctrica, Electrónica y de Telecomunicaciones Universidad Industrial de Santander Bucaramanga, Santander

Recibido: 10 Febrero de 2015

Aceptado: 20 Febrero de 2016

*Correspondencia del autor: Juan S. López G. E-mail: sebas.lopez@icloud.com
\end{abstract}

\begin{abstract}
Colombia has always been a well-known country in terms of natural resources. In particular, mineral resources have become more and more relevant, because of the interest in oil exploitation. However, the easy-access zones are running out of oil, and the efforts are shifting and focusing towards the exploration of hard-access zones. In order to explore these hard-access zones looking for hydrocarbons, economical and reliable alternative techniques are required.

Seismic tomography is one of them, which allows obtaining sub surface velocity models from seismic acquisitions performed on the Earth's surface.

There are several tools developed for performing seismic tomography. One of them is FMTOMO, which is a tool that solves seismic tomography as an inverse problem, dealing with it as an optimization problem proposed from a linear approximation of the Eikonal equation.

The main focus of this work is to evaluate the results obtained using FMTOMO and computing performance. At the end, it is presented a summary of its strengths and weaknesses.
\end{abstract}

Palabras claves: Seismic tomography, tomographic inversion, parallel processing. 


\section{RESUMEN}

Colombia siempre ha sido conocida por sus recursos naturales. En particular, los recursos minerales se han hecho más y más relevantes debido al interés en la explotación petrolera. Sin embargo, las zonas de fácil acceso se están quedando sin petróleo, y los esfuerzos están cambiando y enfocándose hacia la exploración de zonas de difícil acceso.

Para explorar estas zonas de difícil acceso en la búsqueda de hidrocarburos, se requieren técnicas alternativas confiables y económicas.

Una de éstas es la tomografía sísmica, que permite obtener modelos de velocidad bajo la superficie a partir de las adquisiciones sísmicas realizadas sobre la superficie de la Tierra.

Varias herramientas se han desarrollado para realizar tomografía sísmica; uno de las cuales es FMTOMO, la cual es una herramienta que resuelve tomografía sísmica como un problema inverso, tomándolo como un problema de optimización a partir de una aproximación lineal de la ecuación de la eikonal. El enfoque principal de este trabajo fue el de evaluar los resultados obtenidos mediante el uso de FMTOMO y el desempeño computacional. Al final, se presenta un resumen de sus fortalezas y debilidades.

Keywords: tomografía sísmica, inversión tomográfica, procesamiento en paralelo

\section{INTRODUCTION}

In Colombia, a well-known country for its natural resources, exists a high interest of exploiting fossil fuels given the wide variety of terrains in its lithosphere. However, it is very expensive to explore some difficult-access zones such as off-shore zones (1).

Seismic tomography arises as an alternative to obtain an approximate model of the Earth's surface at a relative low cost. This technique uses seismic sources to propagate energy through a media while locating seismic receivers (e.g. geophones) to sense disturbances reflected from the Earth's subsurface and using the recorded data to estimate a possible velocity model that could reproduce the observed data by propagating energy through it (2).

The geophysicist's community has developed several useful tools to perform seismic tomography (3). One of these tools is FMTOMO, developed by Nicholas Rawlinson at the Research School of Earth Sciences at ANU (Australian National University) (4).

FMTOMO (5) is an open-source software distribution that deals with the forward problem of travel time prediction using a multi-stage Fast Marching Method (FMM) that solves frontier problems of the Eikonal equation and the inverse problem, which consists in adjusting model parameters to satisfy observed data given any imposed regularization.

There are three main applications for FMTOMO: seismic imaging, resolution tests and tomographic inversion as can be seen from (6), (7) and (8).

In this paper, we perform an evaluation of FMTOMO and a general analysis of seismic tomography.

We discuss how to improve computational performance using this tool, including an analysis of parallel computing techniques.

\section{Creating 3D Models Using FMTOMO}

FMTOMO allows the user to construct a model composed by three elements: interfaces at different depths, velocity layers between interfaces and a computational grid for rays to propagate through.

Despite having a handy tool to create those models, there are several limitations related to the model's interfaces. Those limitations are:

- All interfaces must completely span the horizontal dimensions of the model region.

- Interfaces cannot be multi-valued in depth. 
- Node distribution for all interfaces must be uniform.

In addition to the subsurface model, there are two arrays that represent seismic sources and receivers. The subsurface model and the arrays of sources and receivers allow simulating an acquisition.

\section{Forward Problem}

After creating a model, the next step is to set up the acquisition to obtain observed travel times from rays propagating through the model. FMTOMO includes a multi-stage fast-marching method for travel time prediction (9).

FMTOMO performs the ray tracing by executing $f m 3 d$, which takes a defined subset of the model created and the source-receiver arrays in order to generate rays' travel times and Frèchet derivatives. After adding Gaussian noise to those travel times, the forward process is complete.

Even though the process above is done using synthetic data only, the travel times obtained in this phase are considered as the reference prior to new travel times obtained by solving the inverse problem. Hence the name observed travel times.

\section{Inverse Problem}

The following steps illustrate the stages in which the inverse problem is solved using FMTOMO:

1. To construct an initial model MO.

2. To propagate rays through the initial model to obtain model's travel times.

3. To adjust the model parameter values (M1).

4. To calculate time residuals.

5. To repeat steps 1 . through 4. $n$ times.

As each iteration changes the model, its travel times will also differ. Using the difference between the initial model's travel times and the observed travel times, the model's parameter values are adjusted. That adjustment is done by solving an inverse problem.

According to Aki's approach (10), seismic tomography can be presented as a parameter estimation problem.

Using the least squares minimization (11) to find the best fit model, a least squares solution can be obtained by minimizing the prediction error of the solution.

Seismic tomography consists in solving consecutively and iteratively both the forward and the inverse problem.

Despite the number of unknowns of the inverse problem, most of the time is consumed by computing the solution of the forward problem.

There is a high interest among users to reduce the computing time in the propagation process as in (7) and (8) the conducted tests would benefit from this reduced time of computation.

There are two ways to reduce this computing time: one is to improve the hardware itself, the other is to use more efficiently the available resources. Taking advantage of the multi-cored philosophy of computers, one could find ways not to use all cores to do the same process, but to use them in parallel to run several processes simultaneously.

\section{Parallel Mode}

As stated at the end of the previous section, parallel computing can help improving the execution performance by taking advantage of all cores in a computer resembling nodes in a cluster.

Activating the parallel mode in FMTOMO is quite simple; it requires executing $f m 3 d$ on each node or core in which the forward problem is divided. This process can be reviewed from (9).

However, parallelism would be useless if one had to manually execute each process one after another. To avoid this, one can use the GNU tool parallel (12) to execute instructions in each core, or even in different machines.

\section{Test Results}

\section{A. Choosing the model}

To test the capabilities of seismic tomography using FMTOMO, the first step was to choose a model that has certain characteristics of interest such as synclines, anticlines, seismic faults and high velocity intrusions.

\section{B. Constructing the model in FMTOMO}


The reference model was built using grid $3 d g$. To shape the finest details the files were edited by hand to add the characteristics described above.

Figure 1(a) shows the model used as reference for all subsequent tests.
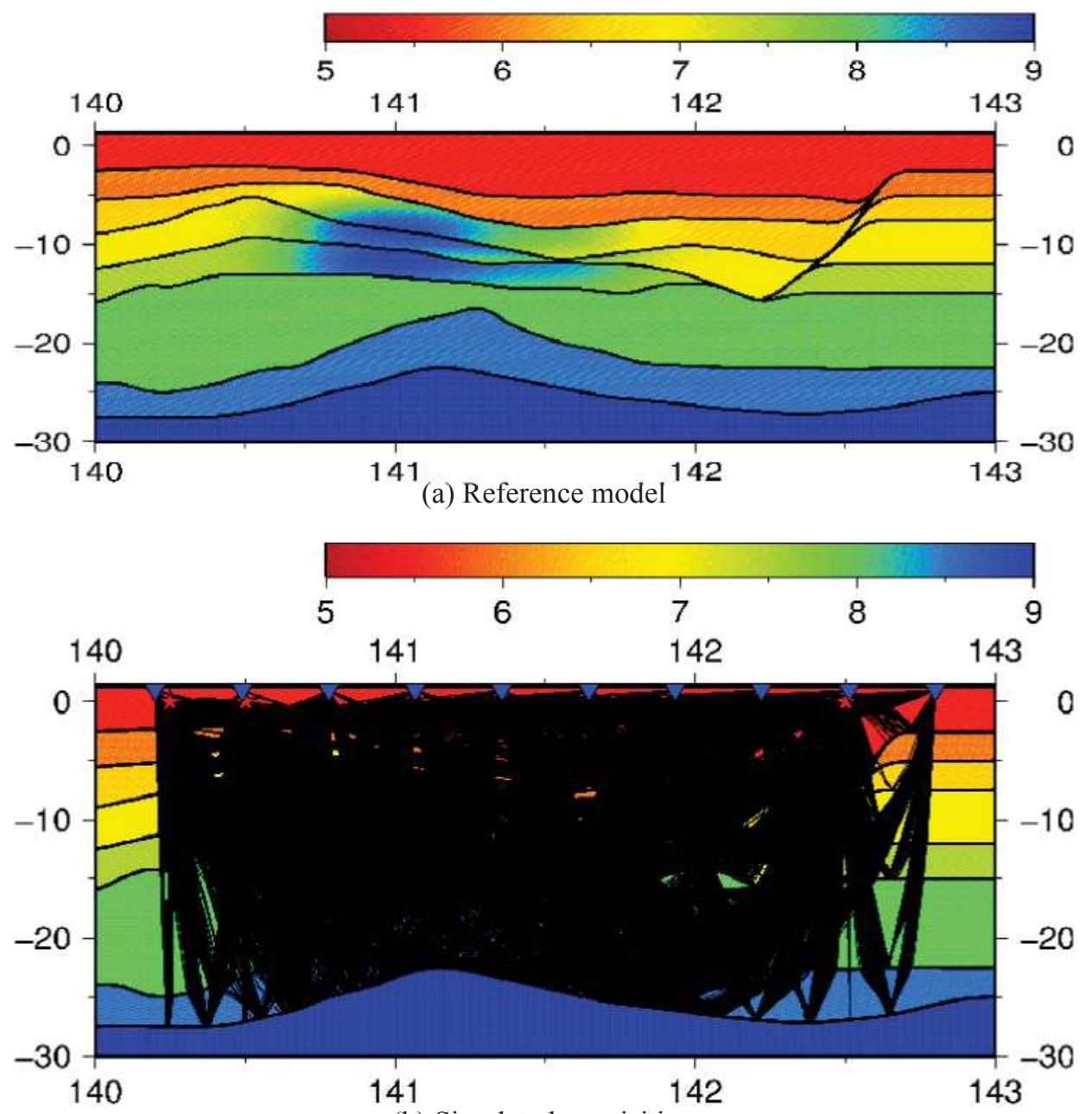

(b) Simulated acquisition

\section{Solving the Forward Problem}

The simulated acquisition shown in Figure 1(b) illustrates the rays traced through the model.

One fact against FMTOMO is that since the model was edited by hand, some rays exhibited errors and were not traced.

\section{Solving the Inverse Problem}

Once the forward problem has been solved and travel times are obtained, what follows is to use that information to create an initial model and modify it iteratively as close as possible to the reference model. Several tests were done with different initial models because the starting point of minimization problems is of extreme importance.
The whole process of selecting initial models can be performed through global optimization techniques, as explained in (13).

The methodology used to select the initial model is quite empirical, but it helps on defining the strengths and weaknesses of FMTOMO.

The tests started with a single-layered model, then, the number of layers was increased to three to prove whether FMTOMO is able or not to forecast the real number of layers and add them to the model.

Unfortunately, because of the discrepancy between the number of layers of the reference model and the 
initial model, it was not possible to obtain a solution by performing an inversion process.

Due to these results, the next test was to start using a model with the same number of layers as the original, all of them horizontally oriented.

Figure 2(a) shows a low-velocity model used as initial model and Figure 2(b) shows the solution model after six iteration steps. A high-velocity zone appears in Figure 2(b), resembling the intrusion in the reference model in Figure 1(a) located around coordinates $(141,-10)$. Another interesting feature is how interfaces tend to pinch-out at coordinates $(142.5,-15)$ being perhaps the effect of the seismic fault in the reference model.

In a final test, the interfaces of the initial model have inclinations depending on how they are oriented in the reference model. For velocities, the test was made from low to high velocities and one model with the exact same velocity distribution as the reference model. Figures 3(a) and 3(b) show the initial and obtained model using low velocities, respectively, while Figures 4(a) and 4(b) show a test using the same velocity distribution as the reference model.
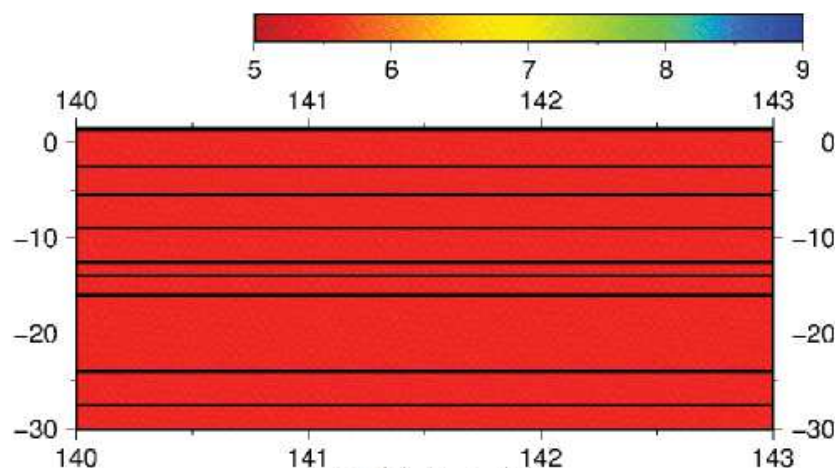

(a) Initial Model.

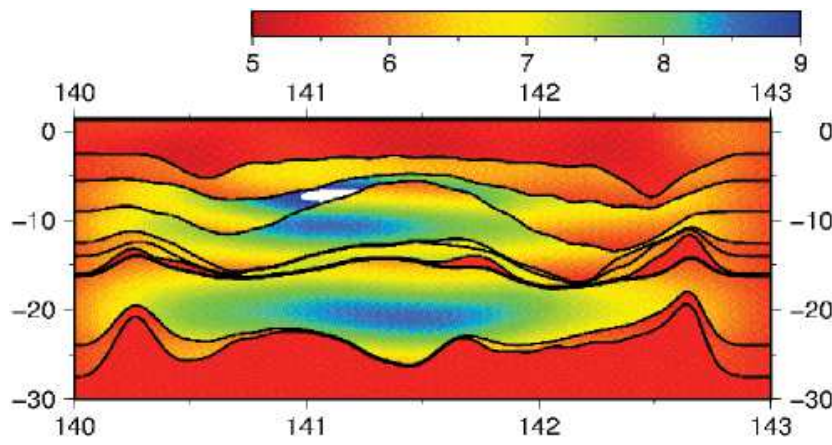

(b) Solution Model

Figure 2. (a) shows a low-velocity with horizontally oriented interfaces model used as $M 0$

and (b) shows the solution model obtained after six iteration steps.

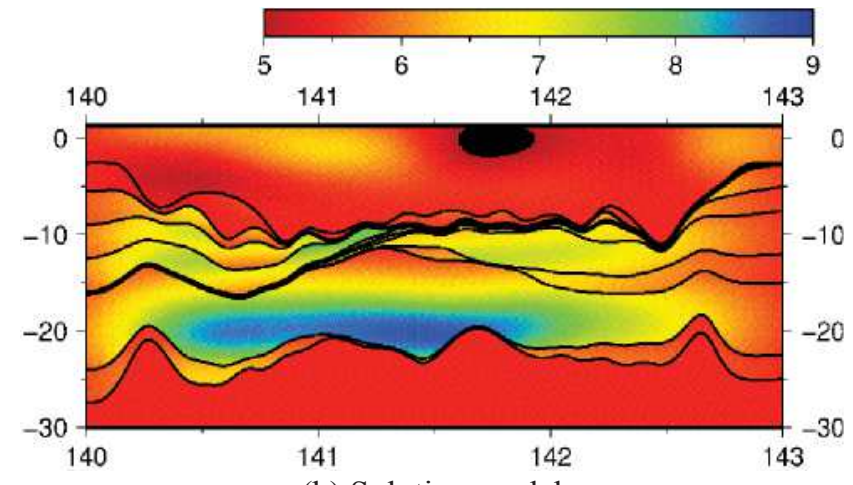

(b) Solution model

Figure 3. (a) shows a low-velocity with diagonally oriented interfaces model used as $M O$

and (b) shows the solution model obtained after six iteration steps.

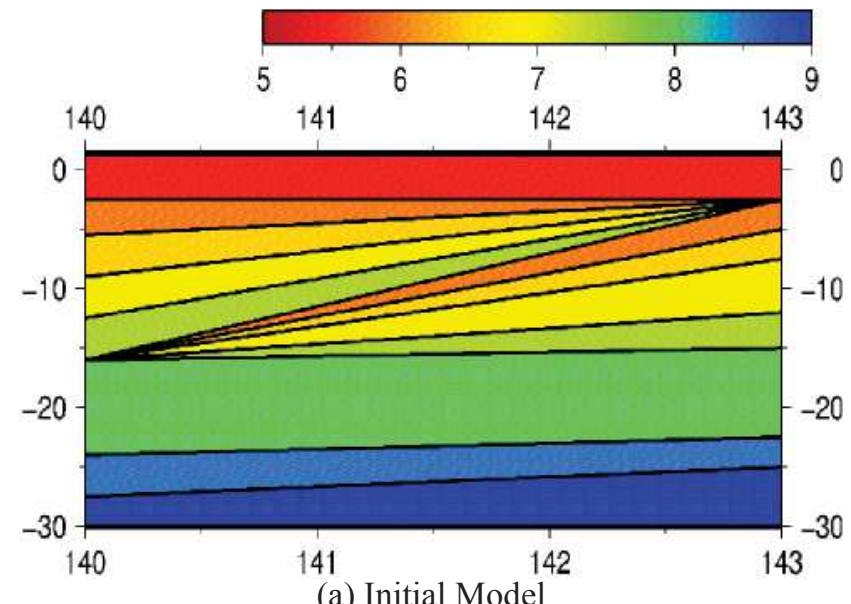

(a) Initial Model

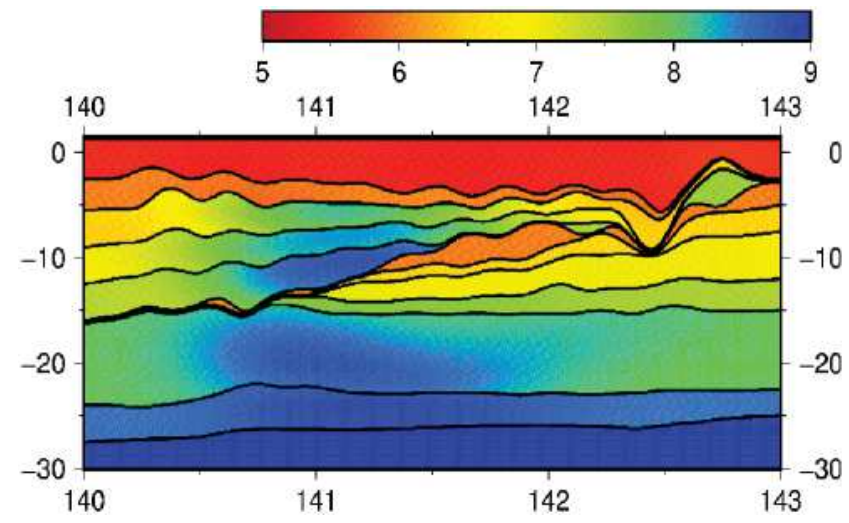

(b) Solution Model

Figure 4. (a) shows the reference velocity model with diagonally oriented interfaces used as $M O$

and (b) shows the solution model obtained after six iteration steps.

In both tests above, it is remarkable how the seismic fault stands out and even the high-velocity intrusion appears in both models (more clearly in the latter than 
the first).

\section{Using GNU Parallel and FMTOMO's Parallel Mode}

Table 1 summarizes the execution time of each FMTOMO's instructions in a set of three cases. All three cases used the same three-layered model, the difference however, laid in the receivers' array which was initially a 10x10 array, the second case used a $30 \times 30$ array and the final test used a 50x50 array. This procedure was done in order to gain complexity by increasing the number of rays propagating through the model and therefore, increasing the amount of data computed.

Table 1. Execution time of three scenarios

\begin{tabular}{lccc}
\hline Instruction & $10 \times 10[\mathrm{~s}]$ & $30 \times 30[\mathrm{~s}]$ & $50 \times 50[\mathrm{~s}]$ \\
\hline arraygen & 0.077 & 0.030 & 0.021 \\
grid3dg & 0.424 & 0.252 & 0.427 \\
moddata & 0.085 & 0.083 & 0.076 \\
frechgen & 0.004 & 0.051 & 0.044 \\
fm3d & 90.673 & 250.311 & 840.196 \\
synthdata & 0.069 & 0.229 & 0.640 \\
invert3d & 2.814 & 3.700 & 25.818 \\
residuals & 0.067 & 0.038 & 0.113 \\
\hline
\end{tabular}

In all cases, time required to execute the forward problem $(f m 3 d)$ is by far higher than time consumed by any other FMTOMO's tool.

Fortunately, this instruction is highly parallelizable, so that, as stated before, the execution time can be reduced by parallelizing the forward problem or using a more powerful machine.

Table 2. Computers used to execute FMTOMO.

\begin{tabular}{ccc}
\hline & $\begin{array}{c}\text { Laptop Com- } \\
\text { puter }\end{array}$ & $\begin{array}{c}\text { Desktop Com- } \\
\text { puter }\end{array}$ \\
\hline CPU & Intel Core i5- & $\begin{array}{c}\text { Intel Xeon E5- } \\
2430 \mathrm{M}\end{array}$ \\
& 2609 \\
Number of Cores & 2 (emulates 4) & 4 \\
CPU's Frequency & $2.4 \mathrm{GHz}$ & $2.4 \mathrm{GHz}$ \\
CPU's DMI & $5 \mathrm{GT} / \mathrm{s}$ & $6.4 \mathrm{GT} / \mathrm{s}$ \\
CPU's Cache & $3 \mathrm{MB}$ & $10 \mathrm{MB}$ \\
Memory & & \\
RAM & $4 \mathrm{~GB} \mathrm{DDR3}$ & $8 \mathrm{~GB} \mathrm{DDR} 3$ \\
RAM's Frequency & $1333 \mathrm{MHz}$ & $1600 \mathrm{MH}$ \\
\hline
\end{tabular}

We used two different machines (a laptop and a desktop) to execute FMTOMO (see comparison in Table 2 ). As both machines can perform tasks using four cores the exercise was to copy the folder in which the forward problem is solved to four new folders to execute $f m 3 d$ in all folders. Then, the tool parallel is used to simultaneously execute the instructions.

Table 3 shows the time required to propagate rays through the reference model (Figure 1(a)) in each scenario (two different machines with and without parallelizing).

Table 3 Four scenarios of executing $f m 3 d$.

\begin{tabular}{ccc}
\hline FM3D & Laptop Computer & Desktop Computer \\
\hline Not & $13 \mathrm{~m} 57 \mathrm{~s}$ & $9 \mathrm{~m} 19 \mathrm{~s}$ \\
Parallel & $8 \mathrm{~m} 12 \mathrm{~s}$ & $2 \mathrm{~m} 50 \mathrm{~s}$ \\
Parallel & & \\
\hline
\end{tabular}

\section{Discussion}

In all tests performed, the objective was to find a solution model similar to the reference model by trial and error using different initial models that grew in complexity with each trial. The results show that it is essential to know the number of interfaces. The issue turns critical when performing an in-situ acquisition because there is no way to know the so called "reference" model. An alternative could be to let loose constrains surrounding the interface inversion and redirect the efforts towards the velocity inversion. Losing (i.e. not gaining) information about interfaces is a major let down; on the other hand, information about the velocity model is still available and can be estimated with fewer issues than information about interfaces.

It cannot be said that a particular test came up with the closest model to the reference as every solution model has some useful information. That is perhaps the most important result of all, not the solution models viewed as single-answers, but to see them as pieces of a bigger answer. With each test some features appeared or hid in the model, that means that with every obtained model, new initial models M0 could be proposed in order to reinforce an specific characteristic.

Trying different initial models in order to look for features that most of the solution models have in common could be a valuable clue for geophysicists 
to encourage or discourage fossil fuels exploration in certain zones.

It is proved how parallel computing reduces the computation time of a task. The results in Table III show that, as expected, improving the machine and performing the task in parallel, turned into the best-case scenario, while the worst case was to use the slowest machine and not parallelizing the task. It is worth noting that the GPU of the desktop computer was never used, but only its CPU, so that the overall performance in that computer can still be improved.

\section{Conclusions}

\section{A. Seismic Tomography}

The main purpose of seismic tomography is to obtain velocity models that best adjust to a set of travel times, being a complementary tool for seismic imaging processes. Proposing the seismic tomography as an inverse problem allows to find a possible solution by predicting a model that best fits a set of travel times, however, multiple solutions can be obtained and those possible solutions highly depend on the initial model from which the process starts. For that reason, selecting an appropriate initial model can be the difference between finding an acceptable solution to the inverse problem or not.

\section{B. FMTOMO}

\section{1) Advantages:}

- FMTOMO emulates the most important steps in a seismic tomography process: modeling, propagating rays and inverting the obtained data.

- One particular strength of FMTOMO is its capability to solve the inverse problem for velocity grids rather than for interfaces (as seen in Figure 4(b)).

- The parallel mode embedded within FMTOMO opens up a new point of view for seismic problems, which are now not only geophysicist's problems, but have turned to be multidisciplinary problems that can be addressed from different approaches: physical, mathematical and nowadays, computational.

\section{2) Disadvantages:}

- Even though FMTOMO provides a handy tool for creating Earth models, the most refined details have to be added by hand.
- FMTOMO deals poorly with structures such as salt domes, since the interfaces modeled in FMTOMO cannot fold over themselves.

- If the model from which the observations are made is created using FMTOMO, the initial model from which the tomographic process begins must have the same number of interfaces as the reference model.

- Interface inversions can be done using FMTO$\mathrm{MO}$; however the results obtained so far have not been as conclusive as the results obtained by performing velocity inversions.

\section{Parallel Computing}

Table III shows four scenarios in which the boundary scenarios were known from the beginning, but it was uncertain which of the other two scenarios consume less time. The result turns out to be quite surprising, given that using parallel computing the time spent was lower than physically improving hardware (which can be the most expensive solution).

With results from this work, previous works using FMTOMO ( (6), (7) and (8) ) can be complemented from a computational point of view and further research can be aimed to improve the performance of FMTOMO (geophysics' approach) or to increase the level of parallelism and prove the scalability and use of parallel, for example by taking advantage of GPU's or by using a cluster. Future works can be emphasized on reducing the time required to solve the forward problem using the capabilities of graphic processing units programmed to compute in parallel using programming tools such as Cuda.

\section{Acknowledgments}

This work is supported by Colombian Oil Company ECOPETROL and COLCIENCIAS as a part of the research project grants No. 0266-2013. The authors gratefully acknowledge Industrial University of Santander.

Special thanks go to the author of FMTOMO, Nicholas Rawlinson, not only for developing such an useful tool for performing seismic tomography but also for taking the time to reply to our inquiries. 


\section{BIBLIOGRAPHY}

1. Abreo S. Viability of implement the seismic tomography to determine the velocity models of new and / or complex zones over an Alternative Highperformance Computing (AHPC) platform. 2012..

2. Lehman B. Seismic traveltime tomography for engineering and exploration applications: EAGE Publications; 2007.

3. Observatories and Research Facilities for European Seismology. [Online]. [cited 2014 July [Review: July 2014]. Available from: http://www.orfeus-eu.org/software/seismo_softwarelibrary.html.

4. Rawlinson N. Australia National University. [Online]. [cited 2014 July. Available from: http:// rses.anu.edu.au/ nick.

5. Rawlinson N. FMTOMO. [Online]. [cited 2014 July. Available from: http://rses.anu.edu. $\mathrm{au} / \sim$ nick/fmtomo.html.

6. Sager K, Fichtner A. Combining full waveform inversion and traveltime tomography. EGU General Assembly Conference. 2014 May.

7. Korger EIM, Schilndwein V. Seismicity and structure of the $85^{\circ} \mathrm{E}$ volcanic complex at the ultraslow spreading Gakkel Ridge from local earthquake tomography. Geophysical Journal International. 2013 October; 196(1).

8. Evanzia D, Pulliam J, Ainsworth R, Gurrola H. Seismic Vp \& Vs tomography of Texas \& Oklahoma with a focus on the Gulf Coast margin. Earth and Planetary Science Letters. 2014 September; 402.

9. Rawlinson N. Fast Marching Tomography Package: Instruction Manual: Research School of Earth Sciences, Australian National University, Canberra ACT 0200; 2007.

10. Aki K, Lee WHK. Determination of three-dimensional velocity anomalies under a seismic array using first $\mathrm{P}$ arrival times from local earthquakes. Journal of Geophysical Research. 1976 August; 81(23).

11. Aster R. Parameter Estimation and Inverse Problems: Academic Press; 2005.

12. GNU-Project. GNU Parallel. [Online]. [cited 2014 Juky. Available from: http://www.gnu.org/ software/parallel/.

13. Sen K, Stoffa PL. Global Optimization Methods in Geophysical Inversion: Elsevier Science; 1995. 